\title{
Structural Case Assignment in Standard Arabic: A Feature-Based-Inheritance Perspective
}

\author{
Abdul-Hafeed Ali Fakih ${ }^{1}$ \\ ${ }^{1}$ Department of English, University of Ibb, Republic of Yemen \& Department of English, University of Najran, \\ Kingdom of Saudi Arabia (KSA) \\ Correspondence: Abdul-Hafeed Ali Fakih, Department of English, University of Najran, Kingdom of Saudi \\ Arabia (KSA). E-mail:a.hafeed1@gmail.com
}

Received: July 29, $2015 \quad$ Accepted: August 24, $2015 \quad$ Online Published: September 29, 2015
doi:10.5539/ijel.v5n5p1
URL: http://dx.doi.org/10.5539/ijel.v5n5p1

\begin{abstract}
The study seeks to explore structural (nominative and accusative) Case assignment in Standard Arabic (henceforth, SA). The objective is to offer a unified account of structural Case assignment in VSO structures, verbal copular sentences, and SVO structures introduced by the complementizer Pinna in SA. Following Chomsky's (2005) minimalist analysis, I argue that TP and VP are not phases in SA; I assume that CP and vP are the only phases in SA clause structure. Furthermore, I assume that the head C of the CP phase is the source of all the features (edge feature and phi-features) on $\mathrm{T}$ in SA. The paper shows that Case is not assigned by $\mathrm{T}$, but rather by the phase head $\mathrm{C}$ of $\mathrm{CP}$ which is responsible for Case assignment. It shows that Case and phi-features of the subject (the Goal) can be valued either under a long-distance Agree relation when the subject remains in situ in VSO structures or by raising the subject DP from [Spec-vP] to [Spec-TP] in SVO structures introduced by Pinna. Moreover, the accusative Case is assigned to the object under the Agree relation established between the phase head $\mathrm{v}$ and the object. Besides, I argue that there are two subjects in SVO structures introduced by Pinna: the external subject is the preverbal subject which follows Pinna and the internal subject which is a pro(nominal); in such structures I assume that $\mathrm{C}$ assigns two Cases; it assigns an external accusative Case to the preverbal NP and an internal nominative Case to the postverbal pro subject.
\end{abstract}

Keywords: Structural Case, Agree relation, CP phase, probe, goal, edge feature, Standard Arabic

\section{Introduction}

The morpho-syntactic analysis of structural Case assignment in natural language grammar has received considerable attention in the last three decades of generative syntax, in general, and in Standard Arabic, in particular. Case has been the focus of syntactic analysis in Chomsky's (1981-1991) Government and Binding (GB) approach and the Minimalist Program (MP) (1993-2005). Moreover, many attempts and accounts have been made to study and examine Case assignment in SA in the attempt to offer a unified account on the subject under question. This is seen in Mohammad (1990), FassiFehri (1993, 2005), Soltan (2007, 2008), Musabhein (2008), and Al-Balushi (2010), among others. Although their syntactic analyses attempted to provide some insight into Case assignment in SA, they could not offer a satisfactory account because they followed different approaches to syntactic analysis. However, the present study seeks to present a satisfactorily unified account on structural Case assignment in SA based on Chomsky's (2005) recent minimalist analysis (the phase model and feature inheritance approach) which constitutes the Agree Theory. The objective of the paper is to investigate structural Case assignment in SA within Chomsky's (2005) framework, examine the interaction between the Arabic data and the assumptions of the Agree theory, and point out to what extent possible the SA proposed analysis can contribute to the understanding of the minimalist theory, given the current challenges posed by minimalism. Besides, there is a need to provide a simple unified analysis of structural Case assignment in SA for the Arab learners of English language as well as for the learners of Arabic from other languages.

The study is organized into five sections. Section 2 reviews the previous studies on the subject under discussion and surveys the pre-minimalist as well as the recent minimalist analyses on structural Case assignment in English and SA. Section 3 discusses the Arabs' various accounts on structural Case assignment in SA. Sections 4 presents an alternative analysis. It explores structural Case assignment in SA within Chomsky's (2005) phase model and feature inheritance approach. Besides, it shows how structural Case assignment can be treated in VSO 
structures, verbal copular sentences, and SVO structures introduced by Pinna in SA. It also proposes how the unvalued uninterpretable features of nominative and structural Cases are valued and deleted in SA syntax. Section 5 summarizes the findings of the study.

\section{Literature Review}

A closer look at the Government and Binding (GB) and the Minimalist Program (MP) analyses reveals the fact that there are different syntactic accounts which have attempted to account for structural Case assignment in generative syntax. In this section I review the previous analyses conducted in different approaches to syntactic analyses in order to present the relevant accounts on structural Case assignment in Standard Arabic and English.

\subsection{Pre-Minimalist Analyses: Case Assignment under Government}

In the GB approach, Chomsky $(1981,1982)$ assumes that Case is assigned to nominals under government, or in a Spec-head configuration. The GB literature shows that Chomsky (1981) has drawn a clear-cut distinction between structural Case and inherent Case. Chomsky deals with Case in terms of structural configurations, where the Case assigner has to c-command the Case assignee. Chomsky (1981) argues that inherent Case depends on the thematic relations between the Case assigner and the Case assignee. Structural Case constitutes both nominative and accusative Case. According to Chomsky, nominative Case is assigned to the subject DP by $\mathrm{T}$ (ense) while accusative Case is assigned to the object DP by the transitive verb. Hence, nominative Case has to do with the tense and agreement patterns on the verb morphology. In other words, Chomsky (1981, 1982) observes that Case is assigned in certain structural configurations. That is, it is obtained under two syntactic structural representations: (i) Spec-head configuration, and (ii) head-complement configuration. This can be schematized in the following syntactic representation in (1).

1.

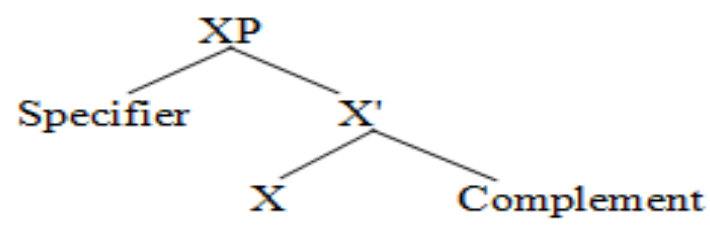

As shown in (1) $\mathrm{X}$ is the head which assigns accusative Case to its complement and nominative Case to Specifier. Given the configuration in (1), the head which assigns Cases-commands the NP to which the Case is assigned.

Furthermore, in the GB framework, the Spec-head relation was assigned for Case assignment and agreement purposes while the second relation, i.e., head-complement, took advantage of the notion of 'government'. According to the Principles and Parameters (P\&P) of Chomsky (1991), nominative Case assignment and the subject-verb agreement were assumed to be the outcome of the Spec-head relation between the head INFL of IP and the DP in Spec of IP. This can be illustrated in (2) below.

2 .

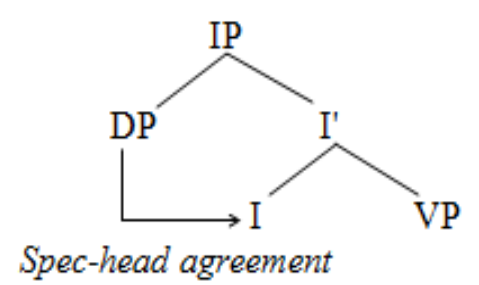

On the other hand, accusative Case assignment and object-verb agreement were postulated to be the direct result of the agreement relation between a head and its complement, i.e., between a verb and its DP object, as illustrated in (3) below. 
3.

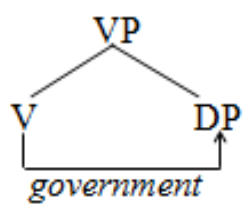

Moreover, cross-linguistic analysis of structural Case assignment and agreement phenomena indicated that the notion of government had to be reconsidered in order to account for Case assignment and subject-verb agreement in VSO languages, as has been seen in Sproat (1985) for Welsh and Mohammad (1990) for Standard Arabic. Further, similar analyses were proposed for VSO languages in Uriagereka (1989) and Raposa and Uriagereka (1990). This can be demonstrated in (4).

4.

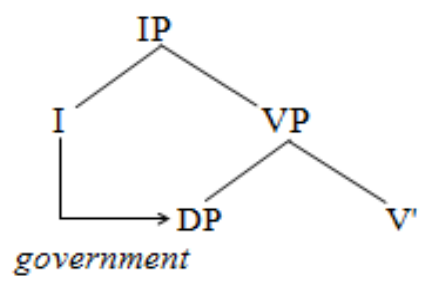

The syntactic representation in (4) shows that in languages with VSO word order, the head I(NFL) was assumed to be able to govern the subject DP in the specifier position of VP. In this regard, agreement features on the verb and Case assignment on the DP are accounted for neatly in the GB framework.

Furthermore, one of the main contributions of Chomsky's (1981) Case theory is Case Filter, which plays a prominent role in the derivation of syntactic structures. However, Chomsky (1986b) argues that the Case Filter follows from a general condition, namely the Visibility Condition which assumes that Case correlates with theta role assignment. That is, a DP has to be assigned Case in order to be visible for theta-role assignment.

\subsection{Earlier Minimalist Analyses}

The emergence of Chomsky's (1993) Minimalist Program (MP) led to a radical departure from the GB approach. The MP suggested an elimination of the asymmetry in the syntactic configuration in order to provide a unified account for structural Case assignment cross-linguistically. Chomsky (1993) proposes a Spec-head framework for the minimalist analysis of structural Case assignment and also calls for the deletion of the notion of government from the theory of grammar.

Furthermore, it was in Pollock's (1989) influential work of Split-INFL Hypothesis that subject-verb agreement and Nominative Case assignment were proposed to be a reflex of a Spec-head agreement relation between the subject and an Agrs (for $\mathrm{Agr}_{\text {SUBJECT }}$ ) head. On the other hand, object-verb agreement and accusative Case assignment were postulated to result from a Spec-head relation between the object and an Agro (for Agr $_{\text {OBJECT) }}$ head. However, Chomsky's (1991) Spec-head relation approach encountered serious challenges as how to establish the required Spec-head relations with regard to the word order of subject, verb and object that appears at the end of the surface structure. Moreover, many attempts and assumptions have been proposed in the account of structural Case assignment, word order and syntactic movement of subject and object in generative syntax, as seen in Koizumi (1995) and Lasnik (1999, 2001).

\subsection{Case Checking/Licensing Approach}

In the earlier analysis of the MP, Chomsky $(1993,1995)$ proposes Case checking/licensing theory in place of Case assignment approach. Chomsky argues that nominals enter the derivation with their Cases specified, but a certain Case has to be checked in a given specifier. The initial analysis of the MP (Chomsky \& Lasnik, 1993) witnesses a radical departure of Case assignment from the GB framework. Chomsky and Lasnik (1993) and 
Chomsky (1995) claim that Case is not assigned but checked in a certain configuration. The major assumption of the MP at this stage is that Case is not assumed to be assigned but rather checked/licensed in a specifier position in the course of the derivation. Chomsky proposes that nominals/NPs are selected from the lexicon with their Cases specified.

Moreover, following Pollock's (1989) Split-INFL Hypothesis, Chomsky $(1991,1993)$ supports the existence of two AgrP projections: AgrsP and AgroP; the former is assigned for subject agreement and the latter for object agreement. Given Case and agreement properties, Kayne (1989) and Chomsky (1993) suggest that AgrsP and AgroP present positions for nominative and accusative Case licensing respectively. However, at a later stage of the minimalist development, Chomsky (1995) dispenses altogether with the AgrP projection from the theory of grammar. Chomsky proposes that VP is immediately dominated by a light verb which has two specifier projections. This can be shown in the representation in (5) which schematizes these two projections.

5.

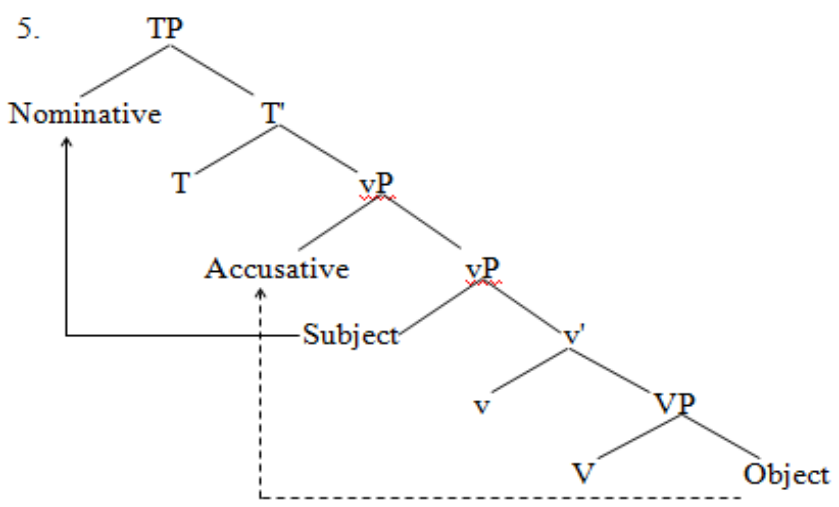

As illustrated in (5), the external argument (i.e., the subject) originates in the inner specifier while the outer specifier is the position where the object checks/licenses its accusative Case. On the other hand, the nominative Case of the subject is licensed in Spec of TP.

However, at a later stage of Case analysis, structural Case assignment witnessed more refinement and improvement by the advent of the MP. Chomsky $(1993,1995)$ assumes that Case has an uninterpretable feature and that this feature is required by the principle of Full Interpretation, where it has to be valued and deleted in the course of the derivation.

\section{Arabs' Accounts on Case Assignment in SA}

It can be observed in the present literature on Arabic analyses that attempts have been made in to order to offer a satisfactory treatment on Case assignment in SA. This is seen in Mohammad (1990) and FassiFehri (1993), among others. Moreover, Soltan $(2007,2008)$ argues against the analysis of tense-inflecting negation in SA on the basis of head-to-head movement (Ouhalla 1991, 1993; Shlonsky 1997; Benmamoun 2000). Soltan proposes an account for the phenomenon based on formal feature licensing relations between syntactic heads. Building on Chomsky 2000, 2001a, 2001b), Soltan proposes that licensing of formal features such as Case and agreement can be derived via the Agree operation. Soltan (2008) indicates that there are typical examples of uninterpretable features, such as $\phi$-features (i.e., person, number, and gender) on $\mathrm{T}$, wh-features on interrogative (complementizer), or Case feature on nominals. Following Chomsky (2005), Soltan indicates that nominative Case on subjects is licensed under the Agree relation with T, while accusative Case on objects is licensed under the operation Agree with the $\mathrm{v}$ head. This can be illustrated in (6) below.

$$
\text { 6. [CP } \left.\quad\left[\begin{array}{llllll}
\mathrm{TP} & \mathrm{T}\left[{ }_{\mathrm{vp}}\right. \text { Subj } & \mathrm{v} & {[\mathrm{v},} & \mathrm{V} & \text { Obj }
\end{array}\right]\right]
$$

On the other hand, Musabhein (2008) discusses Case, agreement, and movement in Jordanian Arabic (JA) with reference to some examples from Standard Arabic. Musabhein (2008) points out that there are two situations in Arabic where Case on a particular noun phrase does not seem to be a result of an Agree. (i) The preverbal noun phrase in SVO structures is nominative only when it is not preceded by any overt Case assigner, and (ii) the complement in the copular sentences carries nominative Case only when the copula is zero. Besides, Al-Balushi (2010) explores the syntax of the licensing of structural Case in SA and argues that structural Case is licensed by a feature, which he calls, Verbal Case (VC). Al-Balushi (2010:1) observes that "structural Case is not licensed 
when VC is not licensed, despite the presence of tense, agreement, and mood." Furthermore, he claims that, like DPs, verbs in SA receive abstract formal licensing in the sense that they have a [VC] feature. He assumes that not only licensing is active in the verbal and nominal system but also argues against the assumption towards eliminating abstract Case from UG. In his analysis of the licensing of structural Case in SA, Al-Balushi (2010) assumes the presence of abstract Case in UG based on his analysis of SA data. Al-Balushi (2010:13) argues "against the proposal that Case is licensed by an I-finiteness feature, since there is no single I-finiteness feature responsible for licensing Case, nor is Case licensed in the abstract of [VC]". His proposal restores the GB and early MP assumption that Case-licensing categories/heads have a Case feature, which is equivalent to [VC].

Although the Arabs' syntactic analyses provided some insight into Case assignment in SA, they could not offer a satisfactory treatment on the subject under discussion because they followed different approaches to syntactic analysis. Furthermore, their treatment seems to be unconvincing and does not discuss structural Case assignment in SA in detail in the same the way this study does. In what follows, however, I attempt to present a satisfactorily unified account on structural Case assignment in SA based on Chomsky's (2005) recent minimalist analysis (the phase model and feature inheritance approach) which constitutes the Agree Theory.

\section{Alternative Analysis}

The major concern of this study is to investigate structural Case assignment in SA within Chomsky's (2005) framework, explore the interaction between the Arabic data and the assumptions of the Agree theory, and propose an alternative analysis which aims to help in the understanding of the minimalist theory of Arabic linguistics, given the current challenges posed by minimalism. Before I present the alternative analysis on structural Case assignment in SA, I need to explore the recent minimalist account on Case, more particularly Chomsky's (2005) feature matching approach on the basis of which the alternative analysis is based on. The feature matching approach is based on Chomsky's (2005) phase model and feature inheritance approach.

\subsection{Recent Minimalist Analysis on Case: Feature Matching Approach}

The licensing of Case has received considerable attention in the last decade of minimalism. The minimalist literature on Case feature shows that there are two proposals on feature which licenses structural Case. The first proposal is advocated in Schiitze (1997) and Chomsky (2001) and assumes that Case is licensed to the DP as a reflex of valuing the $\phi$-features on the Case checking head. The second proposal, on the other hand, is seen in work by Pesetsky and Torrego $(2001,2004)$ and attempts to show that Case is licensed on the DP as a result of valuing a $[\mathrm{uT}]$ feature on $\mathrm{D}^{\circ}$ by $\mathrm{T}^{\circ}$.

Feature matching approach is the most recent analysis of the MP (Chomsky 2000, 2001, 2005). Chomsky proposes that Case is an unvalued uninterpretable feature which needs to be valued and deleted via the Agree relation prior to the LF interface component. It should be noted that Agree is a syntactic operation which establishes a certain relationship between an element $\alpha$ (i.e., Probe) with uninterpretable features $[\mathrm{uF}]$ and an element $\beta$ (i.e., Goal) with matching interpretable features $[\mathrm{F}]$ in the c-command domain of $\alpha$, where the uninterpretable features on the Probe are valued and eliminated by the matching interpretable features on the Goal. Furthermore, Chomsky views Case as part of the Probe-Goal framework. Case feature valuation is obtained under the Agree relation. In the recent minimalist approach, accusative Case assignment is the outcome of the Agree relation between the light verb and the object, while nominative Case is the outcome of the Agree relation between $\mathrm{T}$ and the subject.

Furthermore, what distinguishes the Case assignment model and the Case checking model from the feature matching approach is that Case under the latter does not motivate syntactic movement. That is, the feature matching approach is in agreement with the Economy Principle, where syntactic movement is driven by the need to check particular features of a certain position. Chomsky (2005) suggests that Case is part of the Agree relation and is valued by matching its uninterpretable feature with the corresponding valued interpretable feature on a given functional head in the syntax. In other words, Case is seen as part of the Agree relation between the features of a given head and the features of a nominal.

Chomsky $(2000,2001)$ places a crucial role on the relation of c-command within the Agree model for the functional head (i.e., the Probe) must c-command the nominal (i.e., the Goal) with which it agrees. The minimalist analysis demonstrates that there are features in syntactic representations which are uninterpretbale at LF, such as Case features on nominals and agreement features on verbs. The minimalist assumptions illustrate that if the presence of such features leads to a violation of Full Interpretation Principle then they must be valued and deleted in the course of the derivation to ensure that the derived representation is legible at the interface. As a result, there must be a mechanism in natural language grammar which triggers feature valuation of these unvalued uninterpretable features. Chomsky suggests that the only way to value these uninterpretable features is 
to allow them to be valued against their corresponding interpretable counterparts. If feature valuation is successful, these uninterpretable features will be deleted from the structural representation at LF, thus resulting in a derived structure which converges in the syntax.

Moreover, in earlier minimalist analysis Case and agreement features were licensed in the syntactic structure of Spec-head configuration. But now such features are assumed to be licensed via a primitive operation called Agree relation. In this connection, Chomsky (2001a) suggests that the Spec-head relation has to be dispensed with in the agreement analysis in favour of the head-head relation Agree. The question which can be posed here is: how does the Agree relation work in minimalist syntax? Chomsky sees that Agree is a primitive operation which establishes a relationship between an element $\alpha$ (which he calls a Probe) with uninterpretable features [uF] and an element $\beta$ (which he calls a Goal) with matching interpretable features [F] in the c-command domain of $\alpha$, whereby the uninterpretable features on the Probe are valued by the interpretable features on the Goal, as schematized in (7) below.

7.

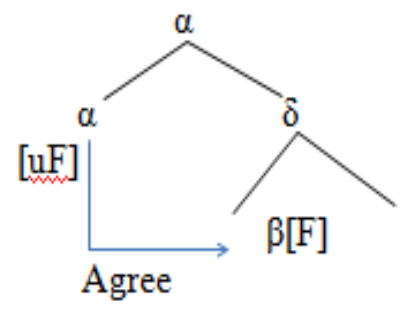

In minimalist analysis, Agree is subject to an "activity" condition, which means that in order to achieve an Agree relation both the Probe and Goal must be "active", in the sense that each one of them has to have an uninterpretable feature or features to value as a result of the operation. That is, the Agree relation between the head $\mathrm{T}$ and a nominal which has an unvalued Case feature is permissible. However, the Agree relation between the head $\mathrm{T}$ and a nominal, which has already its Case feature, is not permitted.

\subsection{Structural Case Assignment in SA and Minimalism}

It can be observed that structural (nominative and accusative) Case assignment is present in SA Case marking system which is overtly morphologically realized; overt Case marking on nominals is a characteristic of SA morpho-syntax which has a rich inflectional paradigm of Case marking and agreement. The overt nominative marker is the suffix $-\mathrm{u}$ while the overt accusative Case marker is the suffix-a; both markers are suffixed to nominals.

Moreover, in this study, I adopt Chomsky's (2005) Agree Theory (i.e., phase model and feature inheritance approach) because it can capture structural Case assignment facts in SA. Following Chomsky's (2005) analysis, I argue along with FassiFehri (2005) that TP and VP are not phases in SA syntax. I also assume that CP and vP are the only phases in SA clause structure. Furthermore, the head T of TP is finite only when it is selected by $\mathrm{C}$, the head of CP. Furthermore, I assume that the head C of CP of SA clause structure is the source of all the features: tense feature (i.e., edge feature) and $\phi$-features on T.

Following Chomsky's (2005) minimalist analysis of the phase theory, I assume that in SA the head C of the CP phase operates downward, probes down via the head T of TP and agrees with the subject, the latter being the Goal. In other words, the heads $\mathrm{C}$ and $\mathrm{T}$ create a C-T complex which functions as a Probe. So, what is the outcome of the C-P complex? What is the consequence of the C-T complex? The answer is that the Case feature valuation on the subject DP as nominative is the outcome of the Agree relation created between the C-T complex and the Goal subject DP. Moreover, Chomsky (2005) indicates that the features of the subject (as the Goal) can be valued either under a long-distance Agree relation when the subject remains in situ in VSO languages or by raising the subject DP from [Spec-vP] to [Spec-TP] in SVO languages. Furthermore, it should be pointed out that the most commonly used word orders in SA are VSO and SVO; the former is treated as the unmarked order while the latter is the marked order.

Furthermore, in demonstrating how structural Case assignment in SA can be captured within Chomsky's (2000, 2001, 2005) minimalist analysis and building on FassiFehri (2005), I assume that Case in SA is an uninterpretable feature which has to be valued and deleted in the process of deriving the structure. I assume that 
in VSO order in SA the subject nominative Case is assigned postverbally under a long-distance Agree between the head C (via T) and the subject while the object accusative Case is assigned via an Agree relation between the functional light $\mathrm{v}$ the object DP. I show that the features of the subject (as the Goal) can be valued either under a long-distance Agree relation when the subject remains in situ in VSO structures or by raising the subject DP from [Spec-vP] to [Spec-TP] in SVO structures in SA. Besides, I adopt Koopman and Sportiche's (1991) Internal Subject Hypothesis in the proposed analysis and argue along with Aoun et al. (1994) that subjects in SA originate in the specifier position of [Spec-vP].

\subsubsection{Structural Case Assignment in VSO Structures}

This section explores structural Case assignment in VSO word order in SA and argues that the subject DP in VSO originates in the specifier position of $[\mathrm{Spec}-\mathrm{vP}]$ and does not raise higher in the clause structure to the specifier position of TP. Given this, I propose the following the clause structure for VSO word order in SA and show how structural (nominative and accusative) Case feature valuation and relevant phi-features are valued and eliminated in the syntax. This can be demonstrated in (8) below.

8.

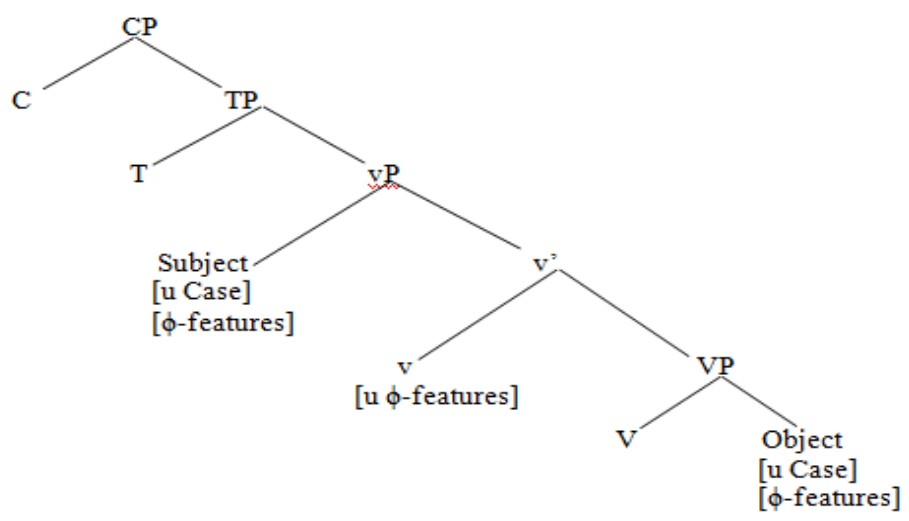

As shown in (8), I argue that the subject DP in VSO in SA does not raise from its base position of [Spec-vP] higher to [Spec-TP]; it must stay in situ because the head C of the CP phase in VSO does not have an edge feature (i.e., tense feature) which triggers syntactic movement. Furthermore, what happens in (8) is that the head $\mathrm{T}$ inherits $\phi$-features from the head $\mathrm{C}$ of $\mathrm{CP}$. However, the head $\mathrm{T}$ lacks an edge feature which initiates the subject movement. Moreover, I argue that the features of the subject (as the Goal) are valued postverbally under a long-distance Agree relation between the phase head C (as the Probe) and the subject via the head T because the subject DP cannot undergo raising in VSO structures in SA. The subject uninterpretable features such as, Case feature and $\phi$-features are valued postverbally in the base position of [Spec-vP].

Now let us illustrate how structural (nominative and accusative) Case is assigned in VSO word order in SA. The examples in (9) below illustrate the point.

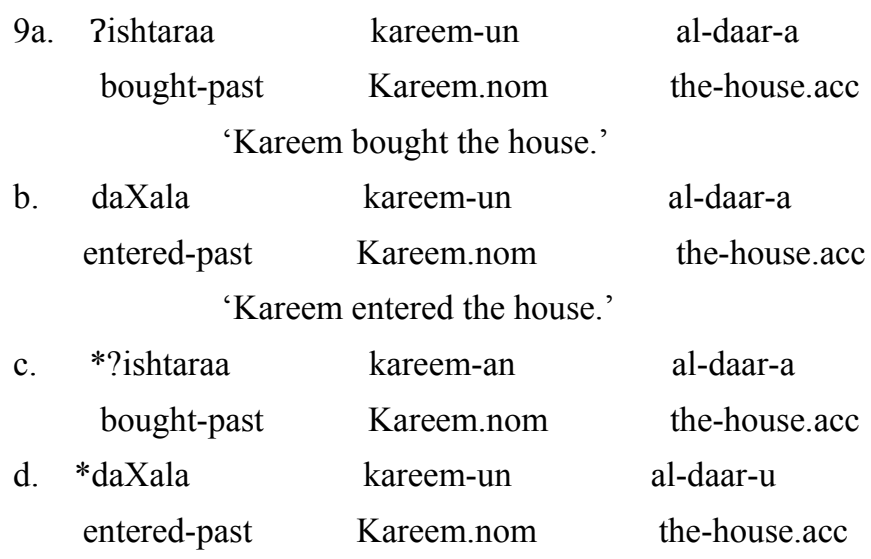

The sentences in (9) show that the subject DP in VSO does not have to move from [Spec-vP] to [Spec-TP]. The reason as to why the subject DP stays in situ can be attributed to the fact that the head C of the CP phase in VSO in SA does not have an edge feature which is responsible forsyntactic movement; this entails that no movement 
of any constituent is required. Further, the subject uninterpretable features (Case and $\phi$-features) are valued and hence eliminated in the subject base-position of [Spec-vP]. On the other hand, the ungrammaticality of $(9 \mathrm{c})$ and (9d) illustrate that the Case feature is not valued and deleted in both (9c) and (9d) because there is mismatch of Case features; this means that the Agree relation is not established between the Probe and the matching Goal. This can support the fact that if the Case feature is not valued properly then the derived structure crashes in the course of the derivation.

On the basis of Chomsky's $(2000,2001,2005)$ analysis of the Agree model, the underlying structure of $(9 a)$ above can be represented in (10) in order to show the syntactic relationship between the heads $\mathrm{C}$ and $\mathrm{T}$ and the subject, on the one hand, and the light $\mathrm{v}$ and the object, on the other.

10 .

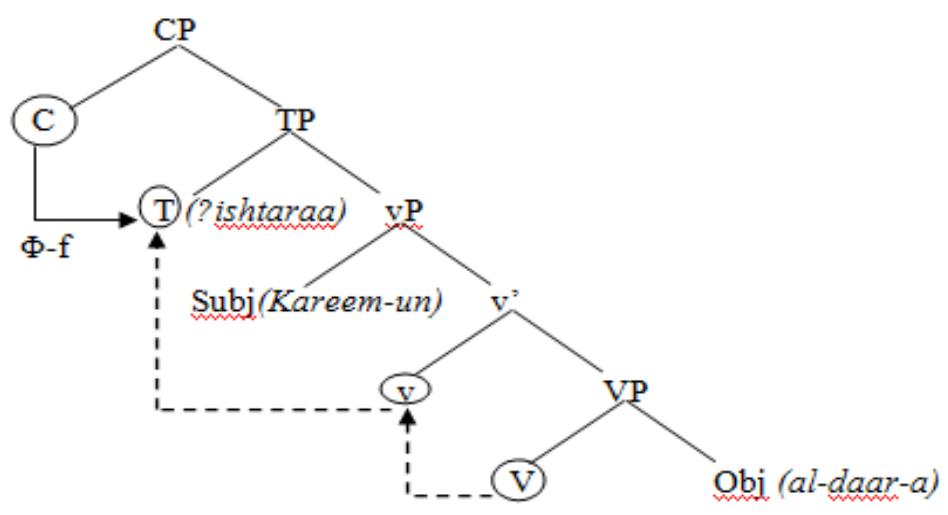

As shown in (10), the head T in VSO word order in SA does not have an edge feature. This means that the subject DP in VSO does not undergo any movement from its base position, [Spec-vP]. Furthermore, the lexical $\mathrm{V}$ has to raise to the functional light v; the latter (i.e., the phase head v) in turn agrees with the object DP and assigns accusative Case to it. It is in this syntactic operation that an Agree relation is established between the phase head v Rishtaraa 'bought' and the object DP al-daar-a 'the house', where the latter is structurally assigned accusative Case, hence all the unvalued uninterpretable features such as, [u Case] and [u $\phi$-features] are valued and hence eliminated in the course of the derivation. As shown in (10) above, the Agree relation establishes a syntactic relation between two active elements (the phase head $\mathrm{v}$ as the Probe and the object DP as the Goal) which have matching unvalued features; it relates a Probe with a matching Goal, thus structural accusative Case is assigned in the syntax.

Besides, it can be observed in (10) above that the subject DP Kareem-un receivesits nominative Case in the base position of [Spec-vP] for the reason that $\mathrm{T}$ in VSO order in SA lacks an edge feature which is responsible for triggering syntactic movement of the subject from [Spec-vP] to [Spec-TP].The[u Case] and [u $\phi$-features] of the subject are valued postverbally under a long-distance Agree relation between the head $\mathrm{C}$ and the subject via the head T since the subject is in situ in VSO order in SA. It is clear in (9) and (10) above that the subject DP Kareem-un in the base position of [Spec-vP] is the searching domain of C, where Agree relation between the head $\mathrm{C}$ (the Probe) and the postverbal subject (the Goal) can be established via the head $\mathrm{T}$ and consequently the Case feature of the subject DP is valued and deleted in the syntax. As a result, the subject movement to a higher position is not required here; if it happens to take place, it seems to violate the economy conditions. Chomsky points out that if $\mathrm{T}$ is selected by $\mathrm{C}$, it projects these features, if not then "it is a raising [...\} infinitival, lacking $\phi$-features" (Chomsky, 2005, p. 10). Once T is probing down for a matching goal, it is valuing the features of C. In other words, $C$ and $T$ constitute a complex probe which agrees with the matching goal. Chomsky $(2005$, p. 10) argues that the matching goal can stay in its position with its uninterpretable features valued and deleted via the Agree relation, "or it can raise as far as SPEC-T, at which point it is inactivated, with all the features valued, and cannot raise further to SPEC-C."

\subsubsection{Verbal Copular Structures in SA}

Let us examine the syntactic behavior of structural Case assignment in verbal copular structures in SA and point out whether such structures behave like their VSO counterparts with regard to Case assignment and feature valuation. It should be pointed out that verbal copular structures are introduced by kaana wa 
khawaatu-haa 'kaana and its sisters' and seem to behave like modal verbs in English. This can be demonstrated in (11) blow.
11a. kaana zayd - un mu'alim - an
was.3sg Zayd.nom teacher.m.sg.acc.indef
'Zayd was a teacher.'
b. kaana-t hind- un mu'alim-at-an
was.3sg Hind-nom teacher.f.sg.acc.indef
'Hind was a teacher.'
c. ?aSbaHa al-rajul-u muhandis - an
became.3sg the.man.nom engineer.m.sg.acc.indef
'The man became an engineer.'
d. aSbaHa-t al-mar'at-u muhandis - at - an
became.3sg the.woman.nom engineer.f.sg.acc.indef
'The woman became an engineer.'

From the sentences in (11) above, it can be observed that kaana wa khawaatu-haa 'kaana and its sisters' seem to behave like normal verbs in SA; they assign a nominative Case to the subject and an accusative Case to the nominal complement. The examples in (11) above show that when the verbal copula is used, we find that the subject and the nominal complement carry cases: the former is nominative and the latter is accusative. A closer look at (11) reveals that these copula sentences contain overt forms of the verbal copulas, which are identical to the normal verbal sentences in VSO structures in SA.

Given the minimalist analysis, it can be pointed out that the source of the nominative Case on the subject is the head $\mathrm{C}$ which transmits its features (phi-features and edge feature) to the head $\mathrm{T}$, while the source of the accusative on the complement is the functional light head $\mathrm{v}$ of the $\mathrm{vP}$ phase. This syntactic operation takes place under the Agree relation, where all unvalued uninterpretable features are valued and hence deleted in the course of the derivation, thus deriving convergent VSO structures, as shown in (11) above. To demonstrate the point let us take (11a) to be represented syntactically on the clause structure of SA in (12) below for more illustration. Case feature valuation in verbal copular sentences in (11) above and (12) below follows the same process like the ones discussed in VSO structures above.

12.

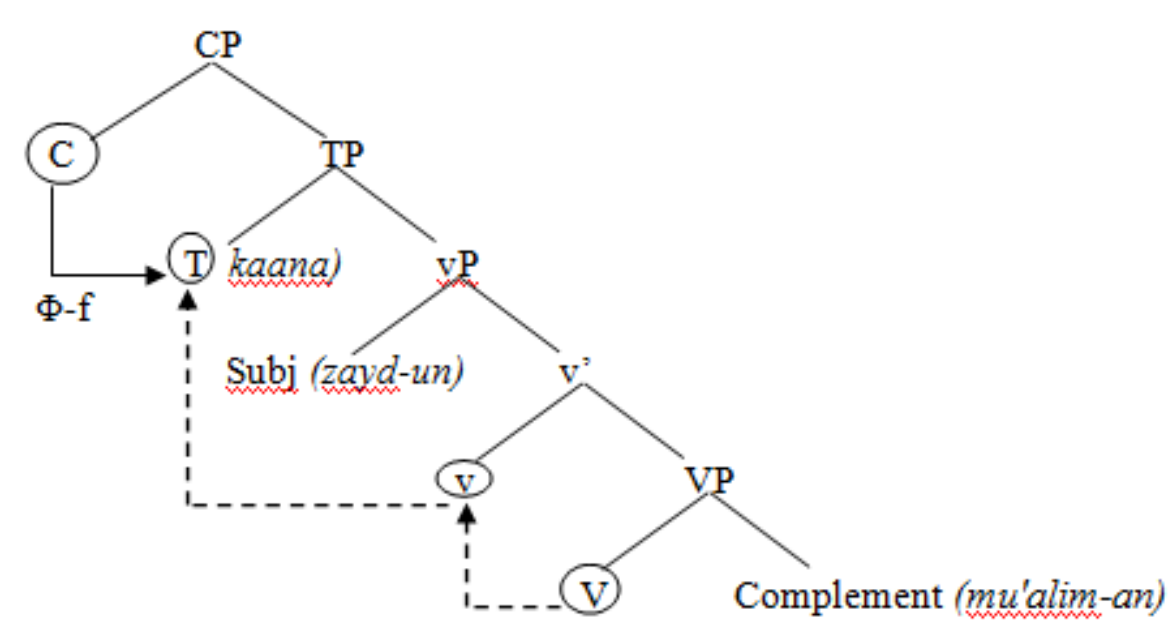


Like VSO structures in SA, (12) shows that the subject DP in verbal copular sentences cannot raise from [Spec-vP] to [Spec-TP] in VSO. As a consequence, the [u Case] and [u $\phi$-features] of the subject are valued postverbally under a long-distance Agree relation between the Probe $\mathrm{C}$ and the Goal subject via $\mathrm{T}$. That is, the subject features are valued in the subject base-position of [Spec-vP]. Thus, the subject DP is assigned nominative Case. Furthermore, the lexical V kaana raises to v; the latter agrees with the object DP and assigns accusative Case to it; an Agree relation is established here and the outcome is that all the unvalued uninterpretable accusative Case and uninterpretable $\phi$-features are valued against their valued counterparts and hence eliminated in the syntax.

\subsubsection{Structural Case Assignment in SVO Structures}

In this section I examine the syntactic behaviour of structural Case assignment in SVO structures introduced by the comlementizer Pinna, which is an accusative Case assigner in SA syntax. It can be observed that there are two subject NPs in SVO structures; the first is the preverbal DP which precedes the verb and the second is the postverbal pro(nominal) subject which follows the verb and shows agreement with it. The questions arise: how can we account for the first preverbal DP and the second pro(nominal) subject in terms of Case assignment and feature valuation? What is the syntactic contribution of the complementizer Pinna in SA grammar? Which one of these two NPs should be treated as the subject of the verb? Let us illustrate the point in (13) below.

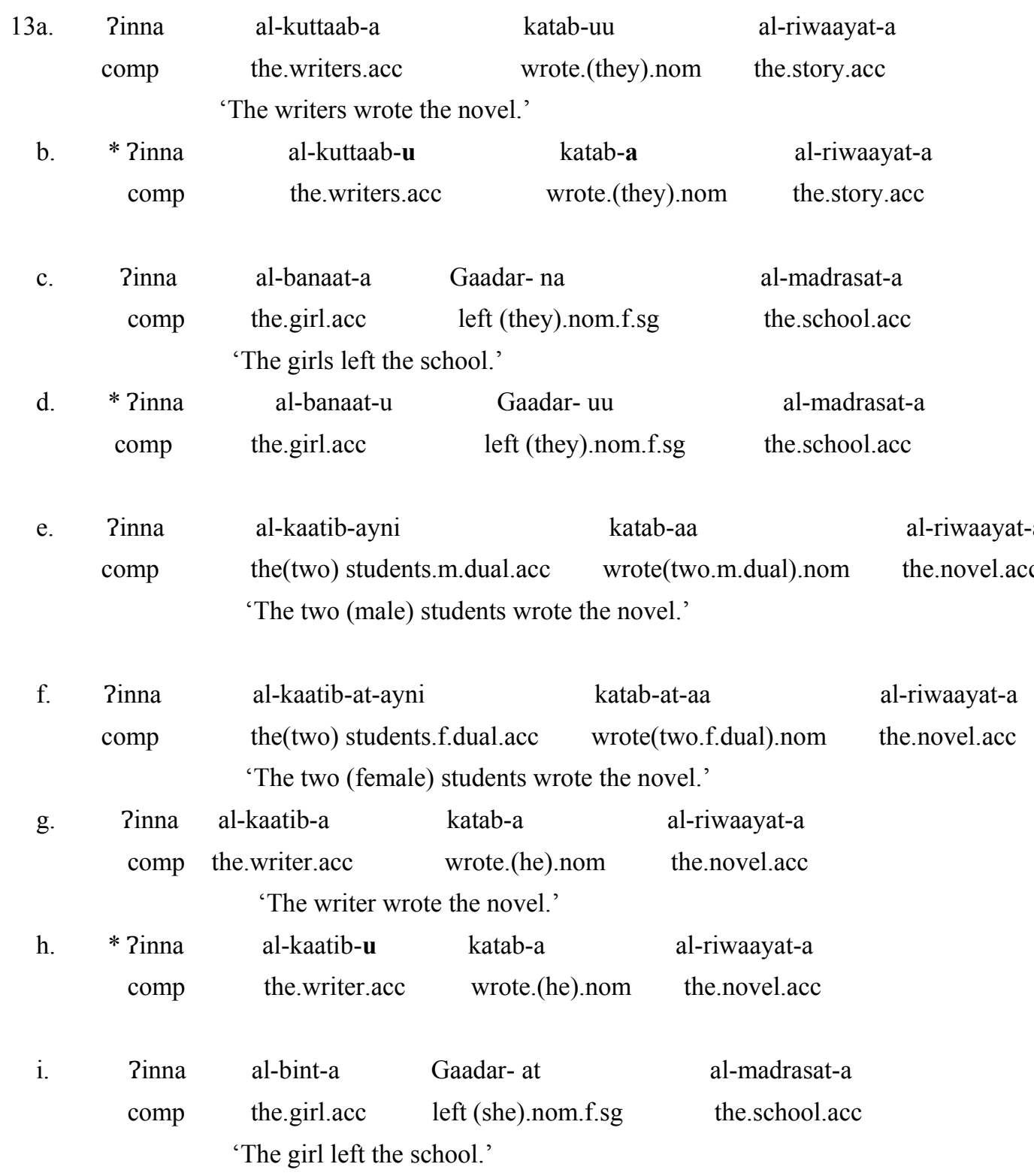

A closer look at SVO sentences introduced by the complementizer Pinna in (13) above reveals that Pinna is an overt Case assigner; it assigns accusative to the first NP which follows it immediately (Sibawayh, 768; 
IbnHisham, 1211; Hassan, 1961). It should be mentioned that Pinna must be followed by an NP, not a VP; it selects an obligatory NP and assigns accusative Case to it. As shown in (13) above there are two subjects in each sentence: a preverbal subject which follows immediately Pinna and a postverbal subject which follows the verb and agrees with it. The traditional Arab grammarians (Sibawayh, 768; IbnHisham, 1211; Hassan, 1961) point out that the complementizer Pinna is a Case assigner; it usually takes two NPs; the first NP is the Topic while the second NP is the Comment. Pinna assigns the Topic an accusative Case and assigns the Comment a nominative Case, as shown in (13a), (13c), (13e), (13f) and (13i) above. Besides, the traditional Arab grammarians state that in SVO sentences, like those in (12) above, assigns the first NP (Topic) an accusative Case and assigns the whole verbal clause (functioning as the Comment) a nominative Case; however, the reverse cannot work in SA grammar, as illustrated in the ungrammaticality of (13b), (13d), and (13h) above which can provide further support for the fact that Rinna assigns its Topic an accusative Case and a nominative Case to its Comment.

On the basis of Chomsky's (2005) minimalist analysis, I argue that Case in SVO structures above is not assigned by $\mathrm{T}$, but rather, it is the phase head $\mathrm{C}$ of the $\mathrm{CP}$ phase which is responsible for Case assignment. I argue along with FassiFehri (2005) that there two subjects in SVO structures in (13) above: (i) the external subject is the preverbal subject which follows immediately Pinna and (ii) the internal subject which is a pro(nominal); the latter follows the verb and is taken to be the postverbal subject. The pro(nominal) subject can be recovered from the verb morphology because SA has a rich inflectional system of agreement where the pro(nominal) subject is realized through rich agreement which involves phi-features (person, number, and gender) and Case. It is this pro(nominal) subject which shows agreement with the verb.

Following the traditional Arab grammarians (Sibawayh, 768; IbnHisham, 1211), and building on FassiFehri (2005), I argue that in each example in (13) above C assigns two Cases; it assigns an external accusative Case to the preverbal NP and an internal nominative Case to the postverbal pro subject. It can be observed that the multiple valuation of Case on different NPs is expected under the assumptions of Chomsky's multiple theory of Agree. Following Chomsky (2005), I assume that CP and vP are the only phases in the clause in SA and that the Agree relation is initiated by the head $\mathrm{C}$ of the CP phase; $\mathrm{C}$ is the source of all features (edge feature and phi-features) for the first accusative Topic and the second nominative pro(nominal) subject; the features of the latter (i.e., pro(nominal) subject) are valued under a long-distance Agree between the phase head C (the Probe) and the subject DP, the Goal. Hence, all unvalued uninterpretable features are valued and deleted in the course of the derivation.

\section{Conclusion}

The study has shown that the features (nominative Case and phi-features) of the subject (as the Goal) can be valued either under a long-distance Agree relation when the subject remains in situ in VSO structures or by raising the subject DP from [Spec-vP] to [Spec-TP] in SVO structures in SA. It has also shown that in VSO structures the nominative Case feature of the subject DP is valued postverbally in [Spec-vP] and that it does not derive syntactic movement, because the head $\mathrm{C}$ of the $\mathrm{CP}$ phase lacks an edge feature (i.e., tense feature) which initiates subject movement. Besides, it has illustrated that postverbal subjects in SA are always invariably nominative in VSO word order. The features (i.e., the edge feature and phi-features) of the subject are valued under a long-distance Agree relation between the Probe $\mathrm{C}$ and the Goal subject via the head $\mathrm{T}$ when the subject is in situ in VSO order. Moreover, the accusative Case assignment is achieved via an Agree relation established between the phase head $\mathrm{v}$ and the object; $\mathrm{v}$ in turn agrees with the object and assigns accusative Case to it. The head $\mathrm{v}$ functions as the Probe and searches for the Goal, the object; thus all unvalued uninterpretable such as, accusative Case and phi-features are valued. Furthermore, the verbal copular sentences seem to behave like VSO structures in SA; they are morpho-syntactically similar in terms of Case and phi- feature valuation.

On the other hand, I have shown in SVO structures introduced by Pinna that Case is not assigned by T, but rather by $\mathrm{C}$ of the $\mathrm{CP}$ phase which is responsible for Case assignment. I have also argued that there two subjects in SVO structures: (i) the external subject is the preverbal subject which follows immediately Pinna and (ii) the internal subject which is a pro(nominal); the latter follows and agrees with the verb and is taken to be the postverbal subject. Moreover, the study has pointed out that in SVO structures introduced by Pinna the head C assigns two Cases; it assigns an external accusative Case to the preverbal NP and an internal nominative Case to the postverbal pro subject. Following Chomsky's multiple valuation of Case on different NPs, I have assumed that $\mathrm{CP}$ and vP are the only phases in the clause in SA and that the Agree relation is triggered by $\mathrm{C}$ of $\mathrm{CP}$; $\mathrm{C}$ is the source of all features (edge feature and phi-features) for the first accusative Topic and the second nominative pro(nominal) subject. In addition, the features of the pro subject are valued postverbally under a long-distance Agree between the Probe (the phase head C) and the Goal, the subject, thus deriving a convergent SVO structure. 


\section{Acknowledgments}

The author would like to thank the anonymous reviewer(s) for their valuable comments and suggestions on the earlier draft of this study. The study has also benefited from the IJEL editor's comments.

\section{References}

Al-Balushi, R. (2010). The licensing of structural Case in SA. Proceedings of the 2010 annual conference of the Canadian linguistic association, 1-15.

Aoun, J., Benmamoun, E., \& Sportiche, D. (1994). Agreement, conjunction and word order in some varieties of Arabic. Linguistic Inquiry, 25, 195-220.

Benmamoun, E. (2000). The feature structure of functional categories: a comparative study of Arabic dialects. Oxford: Oxford University Press.

Chomsky, N. (1981). Lectures on government and binding. Dordrecht: Foris Publications.

Chomsky, N. (1986a). Barriers. Cambridge, Mass: MIT Press.

Chomsky, N. (1986b). Knowledge of language: its nature, origins, and use. New York: Praeger.

Chomsky, N. (1991). Some notes on the economy of derivation and representation. In R. Freidin (Ed.), Principles and Parameters in Comparative Grammar (pp. 417-54). Cambridge: MIT Press.

Chomsky, N. (1993). A Minimalist program for linguistic theory. In K. Hale \& S. J. Keyser (Eds.), The View from Building 20: Essays in Linguistics in Honor of Sylvain Bromberger (pp. 1-52). Cambridge, MA: MIT Press.

Chomsky, N. (1995). The minimalist program. Cambridge, Mass: MIT Press.

Chomsky, N. (2000). Minimalist Inquiries: The framework. In H. Lasnik, R. Martin, D. Michaels, \& J. Uriagereka (Eds.), Step by step. Essays on minimalist syntax in honor of Howard Lasnik. Cambridge, Mass: MIT Press.

Chomsky, N. (2001a). Derivation by Phase. In M. Kenstowicz (Ed.), Ken Hale: a life in language (pp. 1-52). Cambridge, Mass: MIT Press.

Chomsky, N. (2001b). Beyond explanatory adequacy. MIT occasional papers in linguistics, 20, 1-28.

Chomsky, N. (2005). On Phases. Ms. MIT.

Chomsky, N., \& Lasnik, H. (1993). The theory of principles and parameters. In J. Jacobs, A. V. Stechow, W. Stemefeld, \& T. Vennemann (Eds.), Syntax: An international handbook of contemporary research (pp. 506-569). Berlin: Walter de Gruyter.

FassiFehri, A. (2005). The Arabic case for a CP phase. Ms. Mohammad V University. Rabat.

FassiFerri, A. (1993). Issue in the structure of Arabic clauses and words. Dordrecht: Kluwer.

Hassan, A. (1961). an-nahwal-wafi. Cairo: dar al-ma'araef.

IbnHisham. (1211). Qatral-nada waballu al-sada[Dewdrops]. Beirut: Al-MaktabaAlcasriyya.

Kayne, R. (1989). Facets of Romance past participle agreement. In P. Beninca (Ed.), Dialect variation and the theory of grammar (pp. 85-103). Dordrecht: Foris.

Koizumi, M. (1995). Phrase structure in minimalist syntax. Doctoral dissertation, MIT.

Koopman, H., \& Sportiche, D. (1991). The position of subjects. Lingua, 85, $211-258$. http://dx.doi.org/10.1016/0024-3841(91)90022-W

Lasnik, H. (1999). Minimalist analysis. London: Blackwell.

Lasnik, H. (2001). A note on the EPP. Linguistic Inquiry, 32, $356-362$. http://dx.doi.org/10.1162/ling.2001.32.2.356

Mohammad, M. A. (1990). The problem of subject-verb agreement in Arabic: towards a solution. In M. Eid (Ed.), Perspectives on Arabic linguistics I: papers from the First Annual Symposium on Arabic Linguistics (pp. 95-125). Amsterdam: John Benjamins. http://dx.doi.org/10.1075/cilt.63.07moh

Musabhien, M. (2008). Case, agreement, and movement in Arabic: a minimalist approach. Unpublished PhD dissertation, University of Newcastle, UK. 
Ouhalla, J. (1991). Functional categories and parametric variation. London: Routledge. http://dx.doi.org/10.4324/9780203412015

Ouhalla, J. (1993). Subject-extraction, negation and the anti-agreement effect. Natural Language and Linguistic Theory, 11, 477-518. http://dx.doi.org/10.1007/BF00993167

Pesetsky, D., \& Torrego, E. (2004). Tense, Case, and the nature of syntactic categories. In J. Guéron \& J. Lecarme (Eds.), The Syntax of Time. MIT Press.

Pesetsky, D., \& Torrego, T. (2001). T-to-C movement: causes and consequences. In M. Kenstowicz (Ed.), Ken Hale: A Life in Language (pp. 355-426). Cambridge, MA: MIT Press.

Pollock, J.-Y. (1989). Verb movement, universal grammar, and the structure of IP. Linguistic Inquiry, 20, 365-424.

Raposo, E., \& Uriageraka, J. (1990). Long-distance Case assignment. Linguistic Inquiry, 21, 505-537.

Schütze, C. (1997). INFL in child and adult language: agreement, Case, and licensing. Doctoral dissertation, MIT. Cambridge, Massachusetts.

Shlonsky, U. (1997). Clause structure and word order in Hebrew and Arabic, an essay in comparative Semitic syntax. New York: Oxford University Press.

Sibawayh, A. (768). [Reprinted 1973]. Al-Kitaab[The book]. Cairo: Bulaaq Press.

Soltan, U. (2008). Heads of a feather "agree" together: on the morphosyntax of negation in Standard Arabic. In I. Galal \& M. Mustafa (Eds.), On language, literature, and culture: a Festschrift in honor of Prof. Awni Abdel Ra'ouf. Cairo: Al-Karaz Publication House.

Soltan. U. (2007). On formal feature licensing in minimalism: aspects of Standard Arabic morphosyntax. Doctoral dissertation, University of Maryland.

Sproat, R. (1985). Welsh syntax and VSO structure. Natural Language and Linguistic Theory, 3, 173-216. http://dx.doi.org/10.1007/BF00133840

Uriageraka, J. (1989). Head movement and transparency. Ms. University of Massachusetts, Amherst.

\section{Copyrights}

Copyright for this article is retained by the author(s), with first publication rights granted to the journal.

This is an open-access article distributed under the terms and conditions of the Creative Commons Attribution license (http://creativecommons.org/licenses/by/3.0/). 